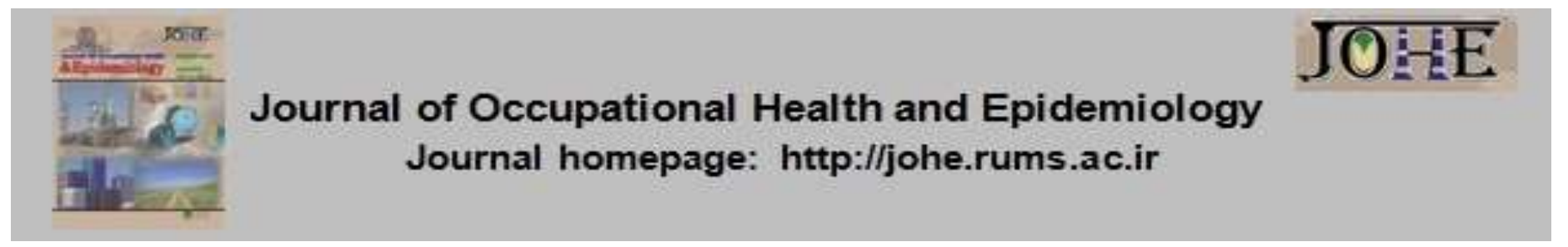

\title{
Musculoskeletal Status and Quality of Life among Faculty Members of Rafsanjan University of Medical Sciences, Iran, 2019
}

\author{
Mohammad Mohsen Taghavi $^{1}$, Ahmad Shabanizadeh², Mehdi Shariati Kohbanani ${ }^{3}$, Akram \\ Mollahoseini ${ }^{4}$, Reza Vazeirinejad ${ }^{5}$, Mohammad Mahdi Taghavi ${ }^{6}$, Zahra Taghi Pour7,* \\ 1- Associate Prof., Dept. of Anatomical Sciences, Social Determinants of Health Research Center, Faculty of Medicine, Rafsanjan \\ University of Medical Sciences, Rafsanjan, Iran. \\ 2- Assistant Prof., Dept. of Anatomical Sciences, Immunology of Infectious Disease Research Center, Research Institute of Basic \\ Medical Sciences, Faculty of Medicine, Rafsanjan University of Medical Sciences, Rafsanjan, Iran. \\ 3- Assistant Prof., Dept. of Anatomical Sciences, Faculty of Medicine, Rafsanjan University of Medical Sciences, Rafsanjan, Iran. \\ 4- MSc in Anatomy, Dept.of Anatomical Sciences, Faculty of Medicine, Rafsanjan University of Medical Sciences, Rafsanjan, Iran. \\ 5- Prof., Dept. of Social Medicine, Social Determinants of Health Research Center, Faculty of Medicine, Rafsanjan University of \\ Medical Sciences, Rafsanjan, Iran. \\ 6- Medical Student, Student Research Committee, Zahedan University of Medical Sciences, Zahedan, Iran. \\ 7- Associate Prof., Dept. of Anatomical Sciences, Faculty of Medicine, Rafsanjan University of Medical Sciences, Rafsanjan, Iran.
}

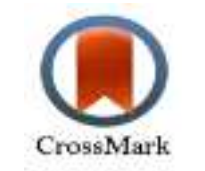

Citation: Taghavi MM, Shabanizadeh A, Shariati Kohbanani M, Mollahoseini A, Vazeirinejad

R, Taghavi MM, Taghi Pour Z. Musculoskeletal Status and Quality of Life among Faculty Members of Rafsanjan University of Medical Sciences, Iran, 2019. JOHE 2020; 9(3):173-9.

\section{Article Info}

* Corresponding author:

Zahra Taghi Pour,

E-mail:

taghipourz@yahoo.com

\section{Article history}

Received: Aug 2020

Accepted: Nov 2020

10.29252/johe.9.3.173

Print ISSN: 2251-8096 Online ISSN: 2252-0902

Peer review under health decreased.

responsibility of Journal of Conclusions: Our results showed that although the work done by the faculty members Occupational Health and Epidemiology

\begin{abstract}
Background: Musculoskeletal diseases are often studied in people with hard occupations, such as in factory workers, but they are less often studied in people with intellectual occupations. Accordingly, this study aims to examine musculoskeletal diseases and their relationship with quality of life among faculty members of Rafsanjan University of Medical Sciences (RUMS) to design corrective exercise and decrease disorders.

Material and Methods: This descriptive study was conducted in 2019, in which 71 out of 179 faculty members of RUMS participated. Also, the participants' level of physical and mental health was assessed using the standard SF-36 questionnaire. The data were analyzed using descriptive statistics and inferential statistics.

Results: The results of the study showed that lordosis and forward head angle were the most prevalent disorders observed in \%94 and \%97 of the participants, respectively. However, the subjects had negligible spinal and pelvic tilts as well. The Pearson's correlation results showed a significant positive correlation between abnormalities of shoulder tilt, forward head angle, and lordosis. It was also found that with an increase in kyphosis, shoulder, and spine disorders, the participants' level of physical and mental Conclusions: Our results showed that although the work done by the faculty members
was very physical in nature, the rate of some musculoskeletal diseases, such as lordosis and forward head angle, was high among them. Therefore, it seems necessary to do necessary planning, such as designing exercise as well as modifying movement patterns, to prevent and to reduce these disorders.
\end{abstract}

Keywords: Musculoskeletal Diseases, Quality of Life, Faculty Members

\section{Introduction}

Musculoskeletal diseases are among the most common problems associated with occupational conditions, which could reduce efficiency of employees in all working groups and impose high costs [1, 2]. Musculoskeletal diseases not only 
affect muscles and bones, but they can also inflict a wide range of damage to the vascular system, tendons, ligaments, and nerves $[3,4]$. Symptoms of skeletal disorders vary from neck and back pain to a burning sensation in shoulders [5]. The incidence rate of skeletal disorders depends on the amount of risk factors, such as repetitive work as well as sitting and standing postures in different occupations [6]. Musculoskeletal diseases affect quality of life in addition to high health care costs for individuals and society [7, 8]. Skeletal disorders affect quality of life in various forms. Dersh et al stated that prolonged pain caused by skeletal disorders for more than six months exacerbates anxiety and stress and exerts a negative effect on self-esteem and emotional wellbeing, thereby reducing quality of life [9].

Musculoskeletal diseases not only cause personal problems for employees, but they have also some economic disadvantages for employers, such as sickness absenteeism, retirement, and disability [10]. In previous studies, including that of Rahimi et al (2014), after evaluating musculoskeletal status of students at a military academy, it was determined that the students had a more appropriate posture than other people in the community due to their regular activities in sports programs [11].

In 2009, the World Health Organization declared that work-related musculoskeletal diseases accounted for more than $10 \%$ of total lost years due to disabilities, and more than $40 \%$ of occupational diseases were related to musculoskeletal diseases in the united kingdom [12]. Similarly, musculoskeletal diseases accounted for 21 to 28 of work absenteeism days in 2017-2018 in the Netherlands, Germany, and the UK, respectively [13]. There are no exact statistics on this subject in Iran; however, the Social Security Organization of Iran paid over $100,000,000,000$ Riyals as insurance fees for treating musculoskeletal diseases in 2012. Besides, in case this amount is added to the costs of muscle diseases, the costs will be many times greater than the mentioned amount [14].

The faculty members of Iran University of Medical Sciences are divided into two main clinical and basic sciences members. Each of the two groups has different tasks and physical activities. Both groups do some teaching and research tasks in the workplace, but depending on the type of the job they are required to perform, they carry out some of their duties during off hours at home, usually with a computer. The use of computers in different sections of the society, especially among faculty members, has increased dramatically, which is the main reason for their inactivity.
Prolonged inactivity reduces blood circulation and leads to muscle stiffness and joint pain, with all of which increasing musculoskeletal diseases [1517]. Clinical faculty members often spend their time at the hospital, clinic, and office to treat and manage patients. Besides, working conditions of dentists differ in the workplace from those in the personal office, and the length of the time they work at the dental clinic is significant. In contrast, nonclinical faculty members spend most of their time solving problems of graduate students' theses. Taking into account differences existing in working conditions of different faculty members mentioned above, it is expected that the incidence rates of musculoskeletal diseases be different among them $[18,19]$.

Musculoskeletal diseases have been evaluated in many groups of workers, including nurses, workers, drivers, military forces, naval force, dentists, and even violinists [6-8, 20]. However, few studies have so far been conducted on musculoskeletal diseases among faculty members of Iranian medical universities as influential people in the society. In this descriptive study, skeletal disorders and quality of life were simultaneously evaluated among faculty members of five faculties affiliated to RUMS, including Faculties of Health, Medicine, Dentistry, Nursing and Midwifery, as well as Paramedical Sciences. People awareness of musculoskeletal diseases could encourage them to improve their movement patterns.

\section{Materials and Methods}

The subjects of this descriptive study included all faculty members of RUMS (male and female) working at 5 Faculties of Health, Medicine, Dentistry, Nursing and Midwifery, as well as Paramedical Sciences, who were randomly referred to in 2019. Exclusion criteria of this study were work experience of less than three years, history of surgery or bone fractures in the vertebral column, congenital abnormalities in the vertebral column and pelvic bones, chronic systemic diseases, and pregnancy [21]. At the beginning of the study, according to the website and statements of the university officials, the total number of the faculty members was 179 , of whom only 71 individuals participated in this study. After random referrals to the members and obtaining written consent forms from them and before measuring variables, the participants were informed about the way the variables were measured, type of the study, and confidentiality of information. Due to the heavy workload, the participants were contacted for measuring their variables when they had enough time for collaboration. Firstly, demographic 
data, such as age, gender, weight, height, and work experience of the participants were recorded. The faculty members might agree to complete the standard questionnaire of quality of life (SF-36) at the same time in the presence of the researcher; otherwise, it would be completed by the participants at a later time. If the participants spent more time, we could have more musculoskeletal variables. Unfortunately, it was not possible to be performed in the study, perhaps due to the tight schedule of the participants and their lack of time. The SF-36 questionnaire has been proven to be effective in uses, such as clinical work, health policy evaluations, as well as research on the general population. Concepts measured by this questionnaire are not related to age, groups, or specific diseases. The purpose of this questionnaire is to assess health status from physical and mental perspectives, which is determined by combining scores of 8 health domains. This questionnaire has 36 items assessing 8 different areas of health, including general health, physical function, role limitations for physical reasons, role limitations for emotional reasons, physical pain, social function, energy and vitality, as well as mental health.

As already mentioned, the questionnaire consists of 36 questions on 8 different subscales, including physical functioning (PF), role of physical status $(\mathrm{RP})$, bodily pain $(\mathrm{BP})$, general health $(\mathrm{GH})$, role of emotions (RE), vitality (V), social functioning (SF), and mental health $(\mathrm{MH})$. In general, by integrating these subscales, two general subscales, namely physical and mental health, are obtained, whose lower score indicates lower quality of life and their higher score indicates higher quality of life [22]. After completing the questionnaire, skeletal variables were measured by the following methods.

To measure thoracic kyphosis and lumbar lordosis, a flexible ruler was used, and the subject was asked to stand shoulder-width apart. Next, the spinous processes of the second lumbar and thoracic vertebrae were identified. The ruler was placed on the vertebral column to produce the form of its curvatures. Next, the ruler was carefully placed on white paper without altering its form to draw the shape of the curvatures on the paper. On the shape drawn on the paper, the abovementioned points were marked as well. To measure the angle of kyphosis, two points of T2 and $T 12$ were connected by a straight line as $L$ line and another line (as $\mathrm{H}$ line) was drawn vertical perpendicular to the arc. Similarly, to measure the lordosis angle, the L2 and S2 points were connected as $\mathrm{L}$ line and the $\mathrm{H}$ line was obtained from the corresponding vertical perpendicular. Then, we put the values of $L$ and $H$ lines in the following formula and the angles of kyphosis or lordosis were obtained: $\Theta=4$ Arctang (2h/l) (Fig. 1D) $[23,24]$.
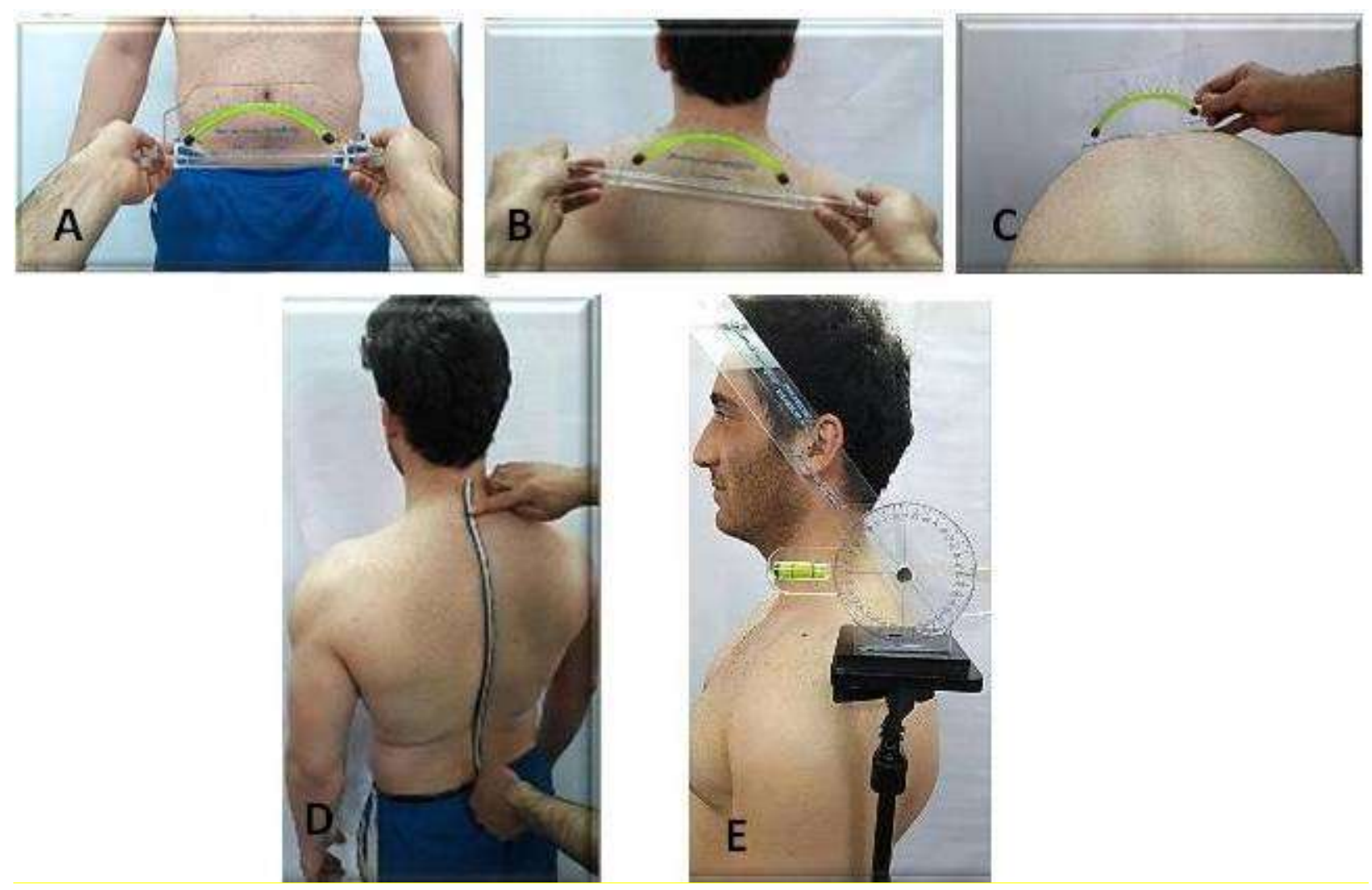

Fig. 1. Measurement of different musculoskeletal variables.

A: Pelvic Tilt; B: Shoulder Tilt; C: Scoliosis; D: Lordosis and Kyphosis; E: Head-to-Front Angle 
A goniometer was used to measure the head-tofront angle, and the subjects were asked to stand in a relaxed position, place their body weight evenly on their legs, and look ahead. Accordingly, fixed and movable arms of the goniometer were positioned along the participants' seventh vertebral neck (parallel to the ground) and the tragus (Fig. $1 \mathrm{E}$ ), respectively [25]. A special device (a pelvic and shoulder inclinometer) with two movable arms was used to measure shoulder and pelvic tilts. Accordingly, the participants were asked to stay in a normal standing position, and by placing two arms of the device on the right and left acromiones, the device degree was recorded (Fig. 1B). In a similar way, to measure the pelvic tilt, the device arms were positioned on the two anterior and superior iliac spines instead of acromiones (Fig. 1A) [26]. To measure scoliosis by a scoliometer, a person was asked to bend forward so that their shoulders would reach the pelvic height. Next, the accelerometer was placed on the lumbar vertebral column, and the device degree was recorded (Fig. 1C) [27-29]. In this study, SPSS V.20 was used, and the significant rate was set at 0.05 .

\section{Results}

From among about 179 faculty members of RUMS, 49 (\%69) male and 22 (\%31) female individuals participated in this descriptive study. The mean age of the faculty members was $42.73 \pm 5.99$ with the age range of $32-60$. In addition, their mean work experience was $15.75 \pm 6.21$ years with the range of 6-33 years. Table 1 shows descriptive results of musculoskeletal status among the participants. According to this table, abnormal lordosis and head angle were seen in the majority of the participants, with 69 (\%97) and 67 (\%94) out of 71 subjects having had these two disorders, respectively. Besides, the mean lordosis and head angle measured were $46.5 \pm 1.23^{\circ}$ and $34.58 \pm 5.24^{\circ}$, respectively, which exceeded normal values, i.e. 45 and $30^{\circ}[28,29]$.

Table 1. Number, mean, minimum, maximum standard deviation, and range of musculoskeletal variables

\begin{tabular}{ccccccc}
\hline & Pelvic tilt & $\begin{array}{c}\text { Shoulder } \\
\text { tilt }\end{array}$ & $\begin{array}{c}\text { Vertebral } \\
\text { tilt }\end{array}$ & $\begin{array}{c}\text { Head } \\
\text { angle }\end{array}$ & Kyphosis & Lordosis \\
\hline & Total & Total & Total & Total & Total & Total \\
& 71 & 71 & 71 & 71 & 71 & 71 \\
\cline { 2 - 7 } Number & Normal & Normal & Normal & Normal & Normal 71 & Normal \\
& 5 & 2 & 1 & 4 & 2 & Abnormal 69 \\
\cline { 2 - 7 } & Abnormal 66 & Abnormal 69 & Abnormal 70 & $\begin{array}{c}\text { Abnormal } \\
67\end{array}$ & $\begin{array}{c}\text { Abnormal } \\
0\end{array}$ \\
\hline Mean & $1.8803^{\circ}$ & $2.2324^{\circ}$ & $2.2817^{\circ}$ & $34.5775^{\circ}$ & $37.8662^{\circ}$ & $46.5000^{\circ}$ \\
\hline Minimum & 0.00 & 0.00 & 0.00 & 20.00 & 30.00 & 40.00 \\
\hline Maximum & 5.00 & 6.00 & 5.00 & 53.00 & 43.00 & 49.50 \\
\hline Std. deviation & 1.00522 & 1.12704 & 1.06815 & 5.24925 & 2.61446 & 1.23346 \\
\hline Range & $0-5$ & $0-6$ & $0-5$ & $20-53$ & $30-43$ & 9.50 \\
\hline
\end{tabular}

Pearson's correlation results showed that there was a significant positive correlation between years of experience and abnormalities of the shoulder tilt, forward head angle, and lordosis (Table 2). Almost similar results were obtained between age and musculoskeletal variables.

Table 2. Pearson's correlation test: Relationships between musculoskeletal status and experience of faculty members

\begin{tabular}{cccc}
\hline \multicolumn{2}{c}{ Variables } & Test statistics & P-value \\
\cline { 2 - 4 } & Shoulder tilt & 0.269 & $0.023^{*}$ \\
\cline { 2 - 4 } Experience & Pelvic tilt & 0.066 & 0.584 \\
\cline { 2 - 4 } & Head angle & 0.374 & $0.001^{* *}$ \\
\cline { 2 - 4 } & Vertebral tilt & 0.179 & 0.135 \\
\cline { 2 - 4 } & Kyphosis & -0.061 & 0.613 \\
\cline { 2 - 4 } & Lordosis & 0.417 & $0.000^{* *}$ \\
\hline
\end{tabular}

** Correlation is significant at the 0.01 level.

* Correlation is significant at the 0.05 level.

The results of the Pearson's correlation test showed that there was a significant negaitive correlation between some musculoskeletal variables and the level of physical and mental health so that with an increase in these variables, the participants' level of physical and mental mental decreased; these variables included shoulder and vertebral tilts as well as kyphosis (Table 3). 
Table 3. Pearson's Correlation Test; Relationships between musculoskeletal status and physical-psychological levels

\begin{tabular}{ccccc}
\hline \multirow{2}{*}{ Variables } & \multicolumn{2}{c}{ Physical health level } & \multicolumn{2}{c}{ Psychological health level } \\
\cline { 2 - 5 } & Test statistics & P-value & Test statistics & P-value \\
\hline Shoulder tilt & -0.270 & $0.023^{*}$ & -0.268 & $0.024^{*}$ \\
\hline Pelvic tilt & -0.162 & 0.177 & -0.199 & 0.096 \\
\hline Head angle & 0.161 & 0.181 & 0.204 & 0.088 \\
\hline Vertebral tilt & -0.462 & $0.000^{* *}$ & -0.497 & $0.000^{* *}$ \\
\hline Kyphosis & -0.671 & $0.000^{* *}$ & -0.718 & $0.000^{* *}$ \\
\hline Lordosis & 0.016 & 0.895 & -0.019 & 0874 \\
\hline
\end{tabular}

** Correlation is significant at the 0.01 level.

${ }^{*}$ Correlation is significant at the 0.05 level.

\section{Discussion}

In this study, we examined musculoskeletal diseases and their relationship with quality of life among 71 faculty members of RUMS in 2019. According to Tables 1 and 2, although the number of abnormal subjects in terms to variables, such as vertebral and pelvic tilts, is almost the same as the variable of lordosis, a deviation of up to 10 degrees in vertebral and pelvis positions is considered normal [30]. In addition, the results of this study showed that an increase in the years of experience significantly increased neck curvature, shoulder tilt, and lordosis in the faculty members (Table 2). On the one hand, the mentioned diseases are more related to prolonged standing in the class and laboratory as well as sitting at the desk; on the other hand, lack of proper mobility, i.e. sedentary work, especially when using a computer, is not limited to office hours, yet members have to spend a lot of time in this position during non-office hours for doing daily work-related affairs. This static siting posture causes many problems, such as decreased blood circulation, stiffness, joint pain, and so on [31]. Similar studies show that the prevalence of musculoskeletal diseases in some occupations is consistent with the present one [32]. A study reported similar musculoskeletal diseases across different groups, such as workers, students, and dentists who had a long sedentary time [33]. Accordingly, the forward head angle reported among bank employees in Kuwait or in faculty members of the College of Applied Medical Sciences, Majmaah University, Saudi Arabia, was consistent with our study results [21].

Analysis of the quality of life questionnaire showed that the majority of the faculty members complained of inadequate physical activity, with the most important reasons for which being lack of time, heavy workload, lack of enough space and sports facilities, as well as laziness. In this regard, Sirajudeen et al found out that only $35 \%$ of the faculty members of Majmaah University had more than 4 hours of light physical activity per week, and that about $45 \%$ of them had heavy physical activity. In addition, their results showed a significant relationship between the forward head angle, lordosis and back pain, wrist skeletal problems, and heavy physical activity, with these problems exacerbated when using a computer mouse for longer periods [21]. Some quality of life outcomes were not achieved as expected; for instance, like the significant negative difference between the shoulder tilt (or vertebral tilt or kyphosis) and mental and physical health levels, similar results were obtained for lordosis and forward head angle. These results could be justified by the fact that the subjects accepted the existing physical and mental conditions. In other words, participants with abnormalities, such as lordosis, do not consider physical and mental conditions in life as causes of this problem. It seems that doing certain activities in the long term causes some musculoskeletal diseases, but because the body adapts to new conditions, a person will not complain of the existing conditions [34].

Malekpour et al reported a significant negative relationship between the rate of musculoskeletal diseases in workers in the auto parts manufacturing industry and their level of physical and mental health, being consistent with results of the present study as shown in Table 3 [35]. Similarly, Rox et al reported that in patients with musculoskeletal diseases, indicators of physical and mental health decreased significantly [36]. Rahimi et al, in their research, reported that some people had a more appropriate posture than other people in the community, which was caused by regular activities based on sports programs [11]. There are also studies not consistent with the results of the recent one; for instance, Biravand et al, in their study, reported no significant relationship between musculoskeletal status and the level of physical and mental health in Iranian Navy Submarine Crews of Bandar Abbas in 2016 [37]. Among possible reasons for different results of Beiranvand's study from previous research, one could refer to the low mean experience or lack of similarity in their participants' jobs. In the present 
study and that of Malekpour, the average experience was 13 and 15.75 years, respectively, while in Beiravand's study, the average experience was 7 years. In the end, it is suggested that musculoskeletal diseases be studied among students and other universities in the form of a regional or national plan.

\section{Conclusion}

The findings of this study generally indicate that an increase in the rate of musculoskeletal diseases among faculty members is inversely related to their level of physical and mental health. In addition, lordosis and forward head angle were the most significant disorders observed among the faculty members, with the situation in most of them having been abnormal. People awareness of musculoskeletal diseases could encourage them to improve their movement patterns.

\section{Acknowledgement}

The author would like to express his sincere gratitude to all faculty members who assisted me in conducting this research. Last but not least, sincere cooperation of the authorities of the Faculty of Medicine and the Vice-Chancellor of Research at Rafsanjan University of Medical Sciences is highly appreciated.

Conflict of interest: None declared.

\section{References}

1. Baldwin ML. Reducing the costs of work-related musculoskeletal disorders: targeting strategies to chronic disability cases. J Electromyogr Kinesiol 2004; 14(1):33-41.

2. Yamada K, Adams H, Ellis T, Clark R, Sully C, Sullivan MJL. Reductions in Fatigue Predict Occupational Re-engagement in Individuals with Work-Related Musculoskeletal Disorders. J Occup Rehabil 2020; 30(1):135-45.

3. Punnett L, Wegman DH. Work-related musculoskeletal disorders: the epidemiologic evidence and the debate. $\mathrm{J}$ Electromyogr Kinesiol 2004; 14(1):13-23.

4. da Costa BR, Vieira ER. Risk factors for work-related musculoskeletal disorders: A systematic review of recent longitudinal studies. Am J Ind Med 2010; 53(3):285-323.

5. Bernard B, Sauter S, Fine L, Petersen M, Hales $\mathrm{T}$. Job task and psychosocial risk factors for work-related musculoskeletal disorders among newspaper employees. Scand J Work Environ Health 1994; 20(6):417-26.

6. Gerr F, Fethke NB, Anton D, Merlino L, Rosecrance J, Marcus $\mathrm{M}$, et al. A prospective study of musculoskeletal outcomes among manufacturing workers: II. Effects of psychosocial stress and work organization factors. Hum Factors 2014; 56(1):178-90.

7. Zaza C. Playing-related musculoskeletal disorders in musicians: a systematic review of incidence and prevalence. CMAJ 1998; 158(8):1019-25.

8. Samad NIA, Abdullah H, Moin S, Tamrin SBM, Hashim Z. Prevalence of Low Back Pain and Its Risk Factors among School Teachers. Am J Appl Sci 2010; 7(5):634-9.

9. Dersh J, Polatin PB, Gatchel RJ. Chronic pain and psychopathology: research findings and theoretical considerations. Psychosom Med 2002; 64(5):773-86.

10. Brown J, Gilmour WH, Macdonald EB. Return to work after ill-health retirement in Scottish NHS staff and teachers. Occup Med (Lond) 2006; 56(7):480-4.

11. Rahimi N, Ghasemi G, Raeisi H, Samavati Sharif MA, Sadeghi M. Investigation of the Prevalence of Musculoskeletal Disorders in Military University Students. Sadra Medical Sciences Journal 2014; 2(4):339-48.

12. Ardahan M, Simsek H. Analyzing musculoskeletal system discomforts and risk factors in computer-using office workers. Pak J Med Sci 2016; 32(6):1425-9.

13. Luger T, Maher CG, Rieger MA, Steinhilber B. Work-break schedules for preventing musculoskeletal symptoms and disorders in healthy workers. Cochrane Database Syst Rev 2019; 7(7):CD012886.

14. Ghahramani A, Summala H. A study of the effect of OHSAS 18001 on the occupational injury rate in Iran. Int J Inj Contr Saf Promot 2017; 24(1):78-83.

15. Intolo $P$, Shalokhon B, Wongwech G, Wisiasut $P$, Nanthavanij S, Baxter DG. Analysis of neck and shoulder postures, and muscle activities relative to perceived pain during laptop computer use at a low-height table, sofa and bed. Work 2019; 63(3):361-7.

16. Sedghi S, Abdolahi N, Azimi A, Tahamtan I, Abdollahi L. A qualitative study on personal information management (PIM) in clinical and basic sciences faculty members of a medical university in Iran. Med J Islam Repub Iran 2015; 29:257.

17. Shahhosseini Z, Danesh M. Experiences of Academic Members About their Professional Challenges: a Content Analysis Qualitative study. Acta Inform Med 2014; 22(2):123-7.

18. Shirzaei M, Mirzaei R, Khaje-Alizade A, Mohammadi M. Evaluation of ergonomic factors and postures that cause muscle pains in dentistry students' bodies. J Clin Exp Dent 2015; 7(3):e414-8.

19. Sadria G, Hosseini M, Rezasoltani A, Akbarzadeh Bagheban A, Davari A, Seifolahi A. A comparison of the effect of the active release and muscle energy techniques on the latent trigger points of the upper trapezius. J Bodyw Mov Ther 2017; 21(4):920-5. 
20. Kemmlert K. Prevention of occupational musculo-skeletal injuries. Labour Inspectorate investigation. Scand J Rehabil Med Suppl 1996; 35:1-34.

21. Sirajudeen MS, Alaidarous $M$, Waly $M$, Alqahtani M. Work-related musculoskeletal disorders among faculty members of college of Applied Medical Sciences, Majmaah University, Saudi Arabia: A cross-sectional study. Int $\mathrm{J}$ Health Sci (Qassim) 2018; 12(4):18-25.

22. Montazeri A, Goshtasebi A, Vahdaninia M, Gandek B. The Short Form Health Survey (SF36): translation and validation study of the Iranian version. Qual Life Res 2005; 14(3):87582.

23. de Oliveira TS, Candotti CT, La Torre M, Pelinson PP, Furlanetto TS, Kutchak FM, et al. Validity and reproducibility of the measurements obtained using the flexicurve instrument to evaluate the angles of thoracic and lumbar curvatures of the spine in the sagittal plane. Rehabil Res Pract 2012; 2012:186156.

24. Khakhali-Zavieh M, Parnian-Pour M, Karimi H, Mobini B, Kazem-Nezhad A. The Validity and Reliability of Measurement of Thoracic Kyphosis Using Flexible Ruler in Postural Hyper Kyphotic Patients. Archives of Rehabilitation 2003; 4(34):18-23.

25. Silva AG, Punt TD, Sharples $P$, Vilas-Boas JP, Johnson MI. Head posture and neck pain of chronic nontraumatic origin: a comparison between patients and pain-free persons. Arch Phys Med Rehabil 2009; 90(4):669-74.

26. Camargo PR, Phadke V, Zanca GG, Ludewig PM. Concurrent validity of inclinometer measures of scapular and clavicular positions in arm elevation. Physiother Theory Pract 2018; 34(2):121-30.

27. Ma HH, Tai CL, Chen LH, Niu CC, Chen WJ, Lai PL. Application of two-parameter scoliometer values for predicting scoliotic Cobb angle. Biomed Eng Online 2017; 16(1):136.

28. Moghadam RE, Rahnama L, Karimi N, Amiri M, Rahnama M. An ultrasonographic investigation of deep neck flexor muscles cross-sectional area in forward and normal head posture. $J$
Bodyw Mov Ther 2018; 22(3):643-7.

29. Gelb DE, Lenke LG, Bridwell KH, Blanke K, McEnery KW. An analysis of sagittal spinal alignment in 100 asymptomatic middle and older aged volunteers. Spine (Phila $\mathrm{Pa} 1976$ ) 1995; 20(12):1351-8.

30. Janicki JA, Alman B. Scoliosis: Review of diagnosis and treatment. Paediatr Child Health 2007; 12(9):771-6.

31. Karsh BT, Moro FBP, Smith MJ. The efficacy of workplace ergonomic interventions to control musculoskeletal disorders: A critical analysis of the peer-reviewed literature. Theor Issues Ergon Sci 2001; 2(1):23-96.

32. Jezukaitis P, Kapur D. Management of occupation-related musculoskeletal disorders. Best Pract Res Clin Rheumatol 2011; 25(1):117-29.

33. van Niekerk SM, Louw QA, Hillier S. The effectiveness of a chair intervention in the workplace to reduce musculoskeletal symptoms. A systematic review. BMC Musculoskelet Disord 2012; 13:145.

34. Marfell-Jones M, Reilly T. Kinanthropometry VIII: Proceedings of the 8th International Conference of the International Society for the Advancement of Kinanthropometry (ISAK). 1st ed. Abingdon-on-Thames, England, United Kingdom: Routledge; 2005.

35. Malekpour F, Mohammadian Y, Moharampour A, Malekpour A. Assessment impact of musculoskeletal disorders and physical activity on quality of life automobile factory workers. Iranian Journal of Ergonomics 2014; 2(1):19-26.

36. Roux $\mathrm{CH}$, Guillemin F, Boini S, Longuetaud F, Arnault N, Hercberg $S$, et al. Impact of musculoskeletal disorders on quality of life: an inception cohort study. Ann Rheum Dis 2005; 64(4):606-11.

37. Beyranvand R, Sani M, Azargoun M. The Assessment of Musculoskeletal Condition and Its Relationship with Years of Service and Level of Physical and Mental Health in NEDAJA Submarine Crews of Bandar Abbas in 2016. Journal of Rafsanjan University of Medical Sciences 2018; 17(1):15-26. 